\title{
Effect of Slope and Packing Ratio on the Behavior of Matchsticks Burnings
}

\author{
Priya Karna1, Roma Karna², Sunil Karna ${ }^{1}$ \\ ${ }^{1}$ Department of Natural Science, Union College, Barbourville, KY, USA \\ ${ }^{2}$ Barbourville High School, Barbourville, KY, USA \\ Email: skarna@unionky.edu
}

How to cite this paper: Karna, P., Karna, R. and Karna, S. (2017) Effect of Slope and Packing Ratio on the Behavior of Matchsticks Burnings. Open Access Library Journal, 4: e3737.

https://doi.org/10.4236/oalib.1103737

Received: June 12, 2017

Accepted: July 10, 2017

Published: July 13, 2017

Copyright $\odot 2017$ by authors and Open Access Library Inc.

This work is licensed under the Creative

Commons Attribution International

License (CC BY 4.0).

http://creativecommons.org/licenses/by/4.0/

(c) (i) Open Access

\begin{abstract}
The experiment was conducted to demonstrate the behavior of fire propagation in wildlands using a matchsticks forest model. A model forest was designed on a flame resistant clay, on top of which matchsticks were inserted and kept vertical to the ground by keeping space between them constant with the help of aluminum grid. The data for distance travelled by fire with time were taken at wide range of slopes from downhill of $-25^{\circ}$ to uphill of $45^{\circ}$ on a model forest of packing ratios 0.08 and 0.04 . The minimum rate of fire spread was observed around $15^{\circ}$ downhill. The data collected from this experiment follow $\tan ^{2} \theta$ and agree with the Rothermel's mathematical model of fire propagation except at elevation above $35^{\circ}$ for low packing ratio.
\end{abstract}

\section{Subject Areas}

Statistics, Forest Science

\section{Keywords}

Wildfire, Packing Ratio, Slope, Fire Propagation

\section{Introduction}

Wildfire is a natural periodic event that cleans up the wild vegetation and is necessary for soil fertilization [1]. However, wildfire often becomes devastating and causes tremendous losses every year. A faster deforestation, wildlife chaos, uncompensated environmental loss, and economical imbalances are some of the impacts of wildlife on society. Fire behavior is a complex phenomenon of aerodynamics, thermodynamics, and combustion physics [2]. Understanding the behavior of fire spread in bush may help control fire spreading, modern forestation, and wildlife husbandry. Many studies have been conducted in past to predict wildfire propagation and to protect wildland from fire damage [3] [4] [5] [6]. Some of 
these reports state that slopes have relatively low effect in the absence of wind on fire spread [7]. However, other reports indicate that slope can significantly affect the rate of fire spread [4], the average size of flames increases with the slope [4], and the rate of fire spread follows $\tan ^{2}$ (slope angle) if there is no wind [6]. Although these studies have reported many important aspects of fire propagation, our studies will further aid understanding of the behavior of fire propagation and provide verification of Rothermel's theoretical model. The rate of fire spread in Rothermel's model is given by the following equation $R=A\left(1+\varphi_{\omega}+\varphi_{s}\right)$, where $A$ is a constant that depends upon the heat source, fuel density, and a reaction intensity, $\varphi_{\omega}$ is a wind coefficient, and $\varphi_{s}=5.275 \beta^{-0.3} \tan ^{2} \theta$, a slope factor, where $\beta$ indicates packing ratio. Since our experiment was performed in no wind condition the rate of fire spread will be taken as $R=A\left(1+\varphi_{s}\right)=A\left(1+B \tan ^{2} \theta\right)$, Where $A$ and $B$ are constants that can be determined from the line of best fit.

In this study, we aim to further investigate and understand fire propagation in forests by designing sets of experiments with a matchsticks forest model at different slopes and packing ratios. Two sets of experiment were designed to measure the rate of fire spread on a matchsticks fuel bed with slopes ranging from $-25^{\circ}$ to $45^{\circ}$ and with packing ratios of 0.08 and 0.04 . All tests were conducted in an open space with temporary side walls to block any wind, and were maintained at $\sim 58^{\circ} \mathrm{F} \pm 3$ ambient temperature, $\sim 76 \% \pm 4$ relative humidity, and at still wind velocity. Arrays of protruding matchsticks in clay bed were used to investigate the behavior of fire spread based on fuel sticks spacing and the fuel bed elevations. Flame length, headfire, and backfire speeds were also considered in predicting fire propagation behavior. Some of the outliers in the data may be assumed to be more influential and were significantly affecting the behavior of fire spread. After analyzing the data by Cook's distance plot with the help of CRAN $\mathrm{R}$ software the outliers were recognized and removed from the data table to predict alternate curve fitting. The data with outliers are shown in results \& discussion section in this article. Since the experiments were conducted only in a laboratory based setup at still wind, these data may or may not predict real forest fire behavior.

\section{Experimental}

Two sets of experiments were conducted on a heat resistant clay as a fuel bed using kitchen matchsticks as a fuel. The uniformity of the matchsticks' fuel size was not verified in this experiment. Matchsticks were arranged in a regular array of $10 \mathrm{~cm}$ by $5 \mathrm{~cm}$ fuel bed. The gap between sticks was $0.50 \mathrm{~cm}$ and $0.82 \mathrm{~cm}$ in set I and set II experiments, respectively. Matchsticks were inserted on the clay bed in such a way that they were vertical to the ground irrespective of the slope. Aluminum grids were used to make equidistant holes on the grid. Grid I consisted of holes of $0.24 \mathrm{~cm}$ at $0.50 \mathrm{~cm}$ apart, and grid II consisted of holes of 0.24 $\mathrm{cm}$ at $0.82 \mathrm{~cm}$ apart. An inclined plane was used to elevate fuel bed to different slopes to replicate hills. Precautions were taken to maintain the gap between the sticks when they were arranged on the fuel bed. Each set of experiments was 
performed on a same fuel bed. The fuel bed has a thickness of $0.50 \mathrm{~cm}$. The wind velocity and ambient temperature readings were taken by an HP866 B anemometer. However, the experiments were conducted only in absence of wind. Packing ratio, the ratio of volume of fuel to the volume of fuel bed including sticks was maintained at 0.08 and 0.04 in set I and set II experiments, respectively. One experiment was also performed on 0.02 ratio but almost no fire spread was recorded on a level bed. One extra matchstick was inserted on the fuel bed in the middle of the first row to ignite the matchsticks' fuel. Flame height, headfire, and backfire speed (not presented here) were also measured to understand a behavior of fire spread.

Videos of burning matchsticks on the fuel bed were taken at slow motion mode of 120 frame per second with an iPhone 6s camera. For easy understanding of fire propagation, we have expressed the fire speed in an arbitrary unit (au). Rate of fire spread was recorded using Tracker, a video analysis and modeling tool software in a manual tracking mode. Figures 1 (a)-(d) below show the experimental setup of the fuel bed before, during, and after fuel burnings. In Figure 1(d) a vertical line represents the height of the flame. All experiments were conducted in an open atmosphere where air flow was blocked with the help of temporary side walls, and were maintained at $\sim 58^{\circ} \mathrm{F} \pm 3$ ambient temperature, $\sim 76 \% \pm 4$ relative humidity, and at no wind velocity.

\section{Results \& Discussion}

Figure 2(a) shows the data generated by Tracker tool as a distance travelled by the fire progressing with time along the $\mathrm{x}$-axis on a fuel bed, and Figure 2(b) is the best linear fit to determine the rate of fire spread. We used a $R$ software to analyze the data once the data were generated from Tracker. The equation of line of best fit in Figure 2(b) is $y=a+b x$, as determined by $R$ software, where $b=14.71 \pm 0.29$, and $a=0.31 \pm 1.2$ for the $40^{\circ}$ slope, and $b=7.65 \pm 0.08$, and $a=-22.69 \pm 0.94$ for the $-10^{\circ}$ slope with the coefficient of determination $99 \%$ for both slopes. Hence, the rate of fire spread was $14.71 \pm 0.29$ for slope at $40^{\circ}$ and $7.65 \pm 0.08$ for the slope $-10^{\circ}$. Similarly, the rate of fire spread was determined for all the other slopes. The slope of a line of best fit was taken as a rate of fire spread or fire propagation velocity. Slope of lines measured from $\mathrm{R}$ was
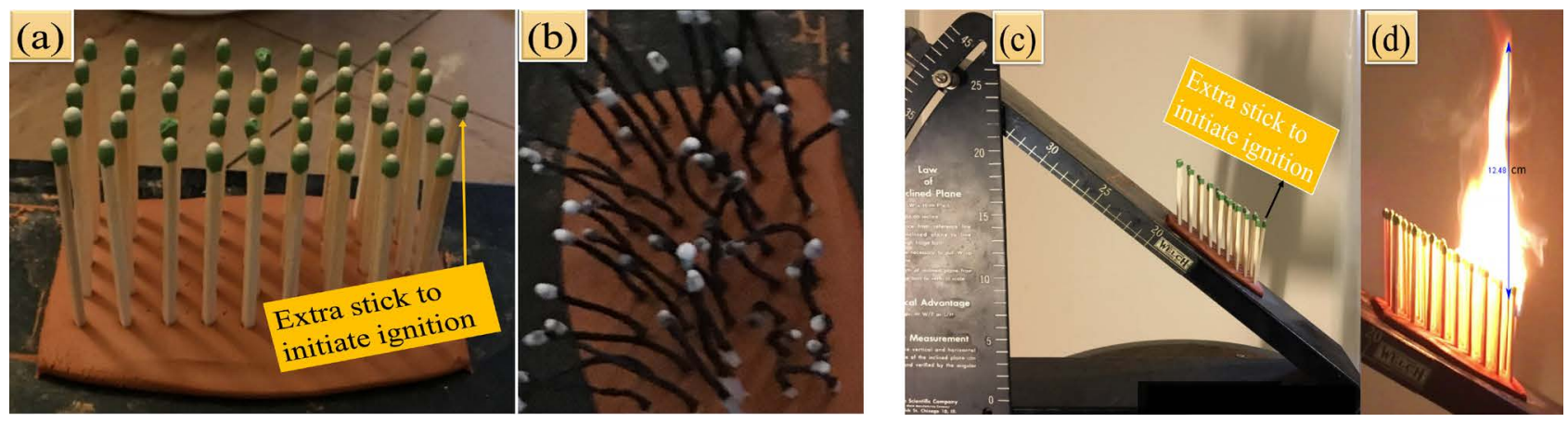

Figure 1. Experimental Setup. (a)-(d) represent experimental setup for matchsticks inserted on a clay bed, curled up burnt sticks, fuel bed at $40^{\circ}$ slope, and burning sticks, respectively. 


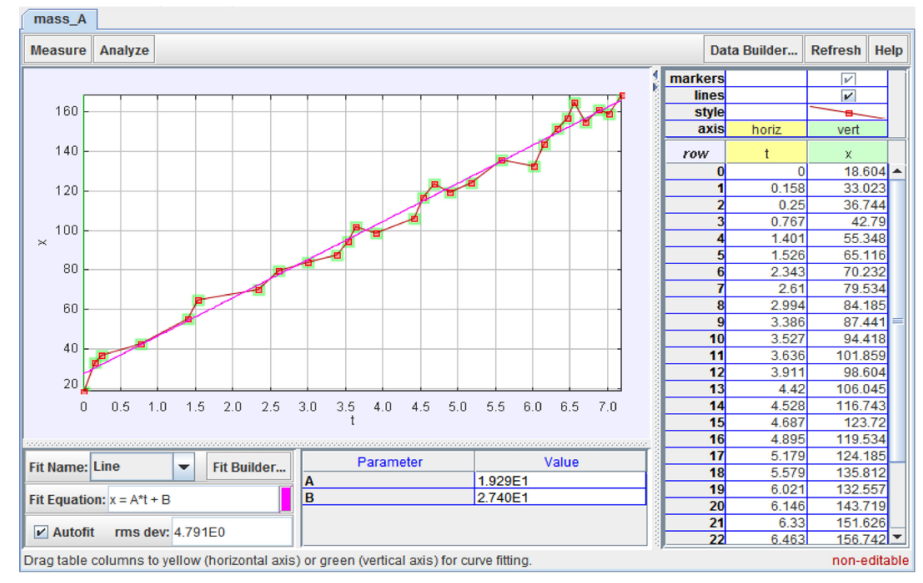

(a)

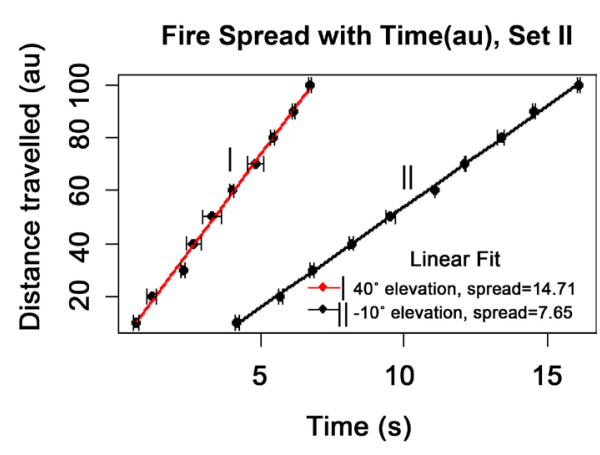

(b)

Figure 2. (a) Data generation by Tracker tool as fire spread with time; (b) Line of best fit for distance travelled by fire with time. Lines I and II represent uphill $40^{\circ}$, and downhill $-10^{\circ}$, respectively.

nearly the same as a slope given by a Tracker tool.

Figure 3(a) and Figure 4(a) are curve fittings on raw data for rate of fire spread with elevation. The equation of curve fittings is given as $y=a+b x+c x^{2}+d x^{3}$, where the coefficients of polynomial are $a=12.7 \pm 1.3, b=0.01, c=-0.002$, and $d=0.00006$ in Figure $3(\mathrm{a})$, and $a=9.33 \pm 0.7, b=0.1, c=0.001$, and $d=-0.00001$ in Figure 4(a). The nature of curves indicates that the rate of fire spread remains almost constant from slope zero to $15^{\circ}$ uphill elevation, increases slowly as elevation increases thereafter, and decreases for downhill as steepness increases as shown in Figure 3(a). The curve in Figure 4(a) shows that the rate of fire spread increases almost linearly with the uphill slope and decreases linearly as downhill slope increases. Such results do not agree with the Rothermel's mathematical model [6]. However, we observed that the fire propagation is slow initially as downslope increases, but becomes faster after burning of a couple of rows. Thus, we decided to analyze our data to locate and remove outliers using Cook's distance plot as shown in Figure 3(b) and Figure 4(b) and found that there were two high influential points in data set I and one point in data set II. Figure 3(c) and Figure 4(c) represent the curve fittings after removal of these outliers from our data set I and II respectively. These curves agree with Rothermel's model of $a\left(1+b \cdot \tan ^{2} \theta\right)$ where $a=10.47 \pm 0.3$, and $b=0.03 \pm 0.01$ chosen from the curve fitting of Figure 3(c), and $a=8.3 \pm 0.3$, and $b=0.1 \pm 0.02$ chosen from the curve fitting of Figure 4(c). For comparison purpose, we have shown our experimental data as blue and red curves together with the mathematical model $a(1+b \cdot \tan \theta)$ and $a\left(1+b \cdot \tan ^{2} \theta\right)$ curves as green and black lines in Figure 3 (d) and Figure 4(d). The shaded region around the curves are standard error in Figure 3(d) and Figure 4(d). We did not find any portion of our data that matches with $a(1+b \cdot \tan \theta)$. Figure $4(\mathrm{~d})$ indicates that the fire spread grows rapidly as the slope increases, but slows down at higher elevation above $35^{\circ}$ for a low packing ratio. Such slowing down of spread may be due to the increment in height difference between fuel materials as slope increases. Such an effect was not observed for high packing ratio of 0.08 , which may be due to 


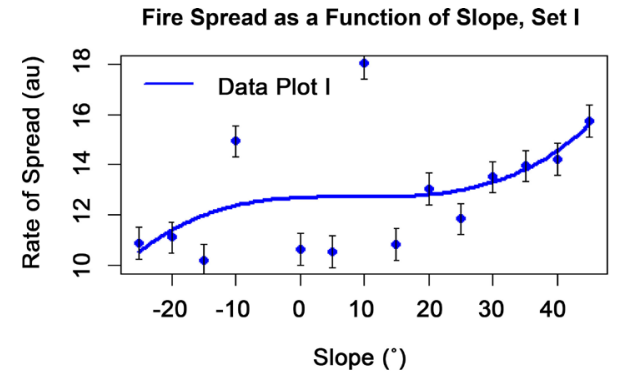

(a)

Curve Fitting after removal of outliers, Set I

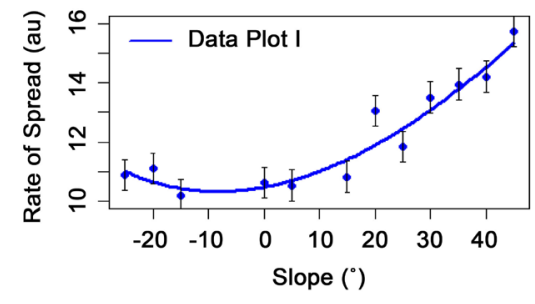

(c)

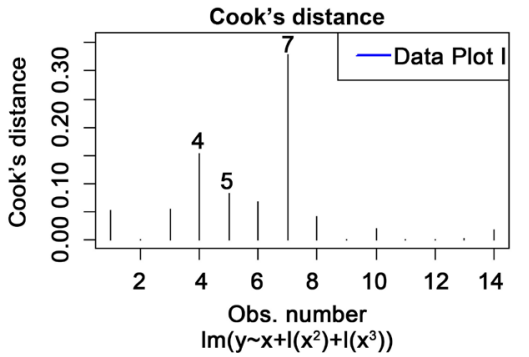

(b)

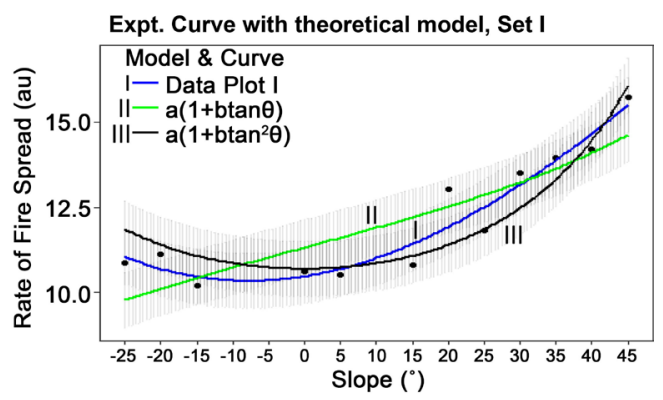

(d)

Figure 3. (a) Curve fitting on raw data of set I experiment (packing ratio $=0.08$ ). The equation of curve fitting is given as $y=a+b x+c x^{2}+d x^{3}$, where $a=12.7, b=0.01, c=-0.002$, and $d=0.00006$. (b) Cook's distance plot for set I data to find high influential points that affect the curve shape. (c) Curve fitting after removal of high influential points from data set I. The equation of curve fitting is given as $y=a+b x+c x^{2}+d x^{3}$, where $a=10.47, b=0.03, c=0.002$, and $d=-0.000008$. (d) Comparing the nature of set I data with theoretical models. Lines I, II, and III represent experimental data of set I, theoretical models $\tan \theta$, and $\tan ^{2} \theta$, respectively.

Fire Spread as a Function of Slope, Set II

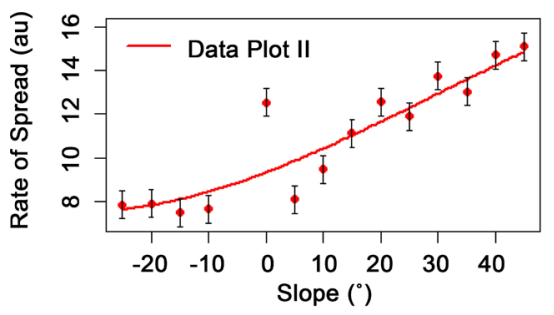

(a)

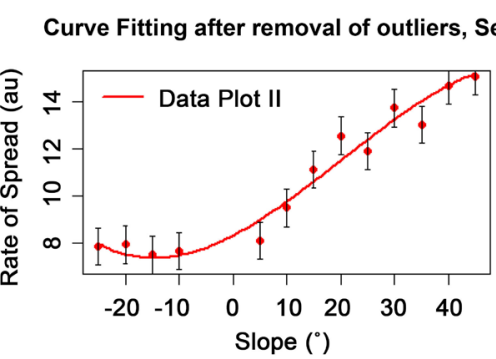

(c)

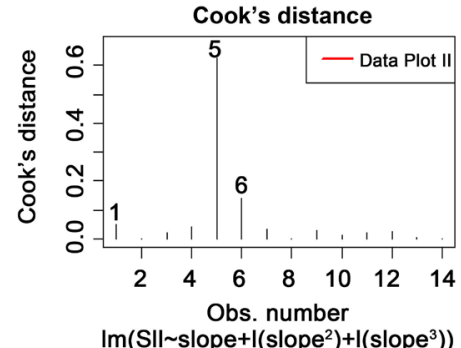

(b)

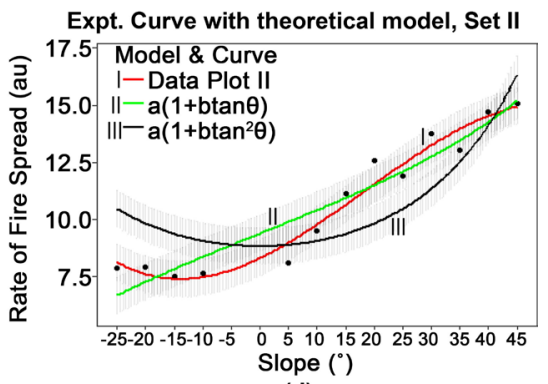

(d)

Figure 4. (a) Curve fitting on raw data of set II experiment (packing ratio $=0.04$ ). The equation of curve fitting is given as $y=a+b x+c x^{2}+d x^{3}$, where $a=9.33, b=0.1, c=0.001$, and $d=-0.00001$. (b) Cook's distance plot for set II data to find high influential points that affect the curve shape. (c) Curve fitting after removal of high influential point from set II data. The equation of curve is given as $y=a+b x+c x^{2}+d x^{3}$, where $a=8.29, b=0.1, c=0.003$, and $d=-0.00005$. (d) Comparing the nature of set II data with theoretical models. Lines I, II, and III represent experimental data set II, theoretical models $\tan \theta, \operatorname{and}^{2} \tan ^{2} \theta$, respectively. 
backfire and headfire that help fire to propagate rapidly in a densely packed fuel bed. The spewing of backfires, headfires, and the whirling of flames may be the causes of outliers in data sets. The factors such as backfire, headfire, non-uniform fuel size, local humidity, and the moisture in the fuel beds may develop a slightly different environment for heat transfer which ultimately deviate this experimental data from a theoretical model.

\section{Conclusion}

In this experiment, we studied the behavior of fire propagation on uphill and downhill forest slopes by designing a clay fuel bed imbedded with matchsticks. Two different packing ratios 0.08 and 0.04 of matchsticks fuel beds were included in this experiment. Our data follow the pattern of $\tan ^{2} \theta$ within the experimental error as predicted by Rothermel [6] except at high elevation for low packing ratio. At low packing ratio, our data indicates the rate of fire propagation slows down with the slopes above $35^{\circ}$. However, at high packing ratio, the rate of fire spread increases with the increase of upslope and is proportional to $\tan ^{2} \theta$. The minimum rate of fire spread was observed around $15^{\circ}$ downslope.

\section{Acknowledgements}

I would like to thank Faculty Research Committee at Union College, Barbourville, KY for providing fund for this project. I would also like to thank Dr. Rice Melinda, Dr. Dan Covington, Department of safety, and Physical Plant at Union College for their assistance with this project.

\section{References}

[1] Punckt, C., Bodega, P., Kaira, P. and Rotermund, H. (2015) Wildfires in the Lab: Simple Experiment and Models for the Exploration of Excitable Dynamics. Journal of Chemistry Education, 92, 1330-1337.http://doi.org/10.1021/ed500714f

[2] Countryman, C. (1972) The Fire Environment Concept. National Wildfire Coordinating Group.

http://caminosfire.com/wordpress/wp-content/uploads/2010/10/pms433_fire_envir onment_countryman.pdf

[3] Weise, D. and Biging, G. (1997) A Qualitative Comparison of Fire Spread Models Incorporating Wind and Slope Effects. Forest Science, 43, 170-180. https://www.fs.fed.us/psw/publications/weise/psw_1997_weise000.pdf

[4] Butler, B., Anderson, W. and Catchpole, E. (2007) Influence of Slope on Fire Spread Rate. USDA Forest Service, Rocky Mountain Research Station, Proceedings RMRSP-46CD, 75-82. https://www.fs.fed.us/rm/pubs/rmrs_p046/rmrs_p046_075_082.pdf

[5] Wagner, C. (1988) Effect of Slope on Fires Spreading Downhill. Canadian Journal of Forest Research, 18, 818-820. http://www.cfs.nrcan.gc.ca/bookstore_pdfs/23539.pdf https://doi.org/10.1139/x88-125

[6] Rothermel, R. (1972) A Mathematical Model for Predicting Fire Spread in Wildland Fuels. USDA Forest Service, Research Paper INT-115, Ogden, Utah, USA, 40. https://www.treesearch.fs.fed.us/pubs/32533

[7] Curry, J. and Fons, W. (1940) Forest-Fire Behavior Studies. Mechanical Engineering, 62, 219-225. https://www.fs.usda.gov/treesearch-beta/pubs/50522 
Submit or recommend next manuscript to OALib Journal and we will provide best service for you:

- Publication frequency: Monthly

- 9 subject areas of science, technology and medicine

- Fair and rigorous peer-review system

- Fast publication process

- Article promotion in various social networking sites (LinkedIn, Facebook, Twitter, etc.)

- Maximum dissemination of your research work

Submit Your Paper Online: Click Here to Submit

Or Contact service@oalib.com 